\title{
Transformational leadership influence on organizational performance through organizational learning and innovation
}

\author{
Paper published in \\ Journal of Business Research
}

Full citation to this publication:

García-Morales, V., Jiménez-Barrionuevo, M. and GutierrezGutierrez, Leopoldo (2012): “Transformational leadership influence on organizational performance through organizational learning and innovation". Journal of Business Research, Vol.65, n.7, pp.1040-1050.

\section{https://doi.org/10.1016/i.jbusres.2011.03.005}

Thank you for your interest in this publication. 


\title{
Transformational leadership influence on organizational
}

\section{performance through organizational learning and}

\author{
innovation \\ Víctor J García-Morales, M Magdalena Jiménez-Barrionuevo, Leopoldo Gutiérrez-Gutiérrez \\ Department of Business Administration, Cartuja s/n 18071, \\ University of Granada, Spain
}

\begin{abstract}
This study analyzes the influences of transformational leadership on organizational performance through the dynamic capabilities of organizational learning and innovation. Although these indirect interrelations are very important for improving organizational performance, previous research has not usually explored them. The study confirms these influences empirically, basing the analysis on a sample of 168 Spanish firms. The results reveal that (1) transformational leadership influences organizational performance positively through organizational learning and innovation; (2) organizational learning influences organizational performance positively, both directly and indirectly through organizational innovation; (3) organizational innovation influences organizational performance positively.
\end{abstract}

\section{Keywords}

- Transformational leadership

- Organizational innovation

- Organizational learning

- Organizational performance

\section{Introduction}

Transformational leadership can be defined as the style of leadership that heightens consciousness of collective interest among the organization's members and helps them to achieve their collective goals. In contrast, transactional leadership focuses on promoting the individual interests of the leaders and their followers and attaining the satisfaction of contractual obligations on the part of both by establishing objectives and monitoring and controlling the results (Bass and Avolio, 2000). Leaders use transactional and transformational behavior to different degrees (Bass, 1999). This investigation focuses on transformational leadership. Theories of transformational leadership emphasize 
emotions, values, and the importance of leadership oriented to encouraging creativity in employees. Employees are a valuable resource in the firm, a resource for which the transformational leader takes responsibility and whose professional development he or she promotes (Bass, 1999; Bass and Avolio, 2000; García Morales et al., 2008a, b).

Transformational leadership attempts to create emotional links with its followers and inspires higher values. Such leadership transmits the importance of having a shared mission and infusing a sense of purpose, direction and meaning into the followers' labor (Bass, 1999). Transformational leadership becomes the motor and transmitter of innovative culture and of the dissemination of knowledge oriented to seeking the best possible organizational performance. The example of transformational leadership committed to the organization's goals and their internalization in its followers seeks to encourage commitment to results on the part of the organization's members (Bass, 1999; Bass and Avolio, 2000). Transformational leaders have charisma, provide inspiration and promote intellectual stimulation (Bass, 1999; Bass and Avolio, 2000; Conger, 1999). Charisma generates the pride, faith and respect that leaders work to encourage their employees to have in themselves, their leaders, and their organizations. Transformational leaders provide inspiration by motivating their followers, largely through communication of high expectations. Such leaders also promote intellectual stimulation by promoting employees' intelligence, knowledge and learning so that employees can be innovative in their approach to problem solving and solutions. Various studies analyze the influence of transformational leadership on organizational performance through intermediate constructs such as culture (e.g., Ogbonna and Harris, 2000), entrepreneurship (e.g., García Morales et al., 2006), knowledge management (e.g.,Gowen et al., 2009), congruence in top management teams (e.g.,Colbert et al., 2008), flexibility (e.g., Rodriguez Ponce, 2007), human-capital-enhancing human resource management (Zhu et al., 2005), competitive strategies (e.g., Menguc et al., 2007), and absorptive capacity (e.g., García Morales et al., 2008a, b). However, understanding of the processes through which the leader exerts this influence is still limited and largely speculative (Bass, 1999; Conger, 1999). This investigation seeks to analyze empirically whether transformational leadership exerts this influence on organizational performance through the intermediate influence of organizational learning and innovation.

Organizational learning is the capability "within an organization to maintain or improve performance based on experience. This activity involves knowledge acquisition (the development or creation of skills, insights, and relationships), knowledge sharing (the dissemination to others of what has been acquired by some), and knowledge utilization (integration of learning so that it is assimilated and broadly available and can be generalized to new situations)" (DiBella et al., 1996, p. 363). Organizational learning is the process by which the organization increases the knowledge created by individuals in an organized way and transforms this knowledge into part of the organization's knowledge system. The process takes place within a community of interaction in which the organization creates knowledge, which expands in a constant dynamic between the tacit and the explicit (Nonaka and Takeuchi, 1995). The development of new abilities and knowledge and the increase in the organization's capability enable organizational learning. Organizational learning involves cognitive and behavioral change. More than ever, organizational learning has become a need rather than a choice. Inability to learn is the reason most firms disappear before forty years have passed (Argyris and Schön, 1996; Senge, 1990). 
The scientific literature proposes different definitions of innovation. This study uses the definition of innovation formulated by the Product Development and Management Association, which analyzes innovation as "a new idea, method, or device. The act of creating a new product or process. The act includes invention as well as the work required to bring an idea or concept into final form" (Belliveau et al.,2002, p. 446). Although research widely prescribes firm innovation as a means of improving organizational performance, many firms do not or cannot develop innovation properly. Researchers urge attention to what enables firms to innovate, to search for answers beyond semiautomatic stimulus-response processes (Zollo and Winter,2002, p.341).

Empirical studies support the relationship between organizational learning and innovation (Bueno et al., 2010; Cohen and Levinthal, 1990; Glynn, 1996; Hurley and Hult, 1998; Ireland et al., 2001; Mezias and Glynn, 1993). Different types of learning and innovation are also related. For example, generative learning is the most advanced form of organizational learning and occurs when an organization is willing to question long-held assumptions about its mission, customers, capabilities, and strategy and to generate changes in its practices, strategies, and values. Such learning forms the necessary underpinnings for radical innovations in products, processes, and technologies (Argyris and Schön, 1996; Damanpour, 1991; Glynn, 1996; Senge, 1990; Senge et al., 1994).

The literature also emphasizes the great importance of organizational learning and innovation for a company's survival and effective performance. Organizational learning is a major component in any effort to improve organizational performance and strengthen competitive advantage. The development of new knowledge, derived from organizational learning, reduces the likelihood that a firm's competencies will become outdated, enabling the competencies to remain dynamic and thus favoring improvement in performance. Organizational learning usually has positive connotations, since this form of learning associates with performance improvements (Argyris and Schön, 1996; Fiol and Lyles, 1985; Inkpen and Crossan, 1995; Ireland et al., 2001; Senge, 1990). Various authors also show that innovation is essential to improving performance and that innovation comes into play in order to improve organizational performance (Argyris and Schön, 1996; Damanpour, 1991; Fiol and Lyles, 1985; Hurley and Hult, 1998; Senge, 1990; Zaltman et al., 1973).

To summarize, this study analyzes the influence of transformational leadership on organizational learning and innovation and emphasizes the importance of providing empirical results that prove these relationships. The model also claims to demonstrate the existence of a positive and significant link between organizational learning and innovation and between these dynamic capabilities and organizational performance. The relatively slight attention paid in practice to these topics contrasts with their importance for technicians and practitioners.

To achieve the objectives, the article develops as follows. Based on previous research, the section on hypotheses proposes a series of hypotheses on the influence of transformational leadership on organizational learning and organizational innovation, the influence of organizational learning on organizational innovation and the influence of both organizational learning and organizational innovation on organizational performance. The method section presents the data and the method used to analyze empirically the hypotheses developed in Spanish firms. The section on the results presents 
the findings. Finally, the section on conclusions and future research discusses the results and points out some of the limitations of this study.

\section{Hypotheses}

\subsection{The influence of transformational leadership on organizational learning and organizational innovation}

Prior studies assert association between leadership and organizational learning (McGill et al., 1992; Senge, 1990; Senge et al., 1994; Tushman and Nadler, 1986). Transformational leadership builds teams and provides them with direction, energy, and support for processes of change and organizational learning (Bass, 1999; McDonough, 2000). This style allows organizations to learn through experimentation, exploration, communication and dialogue (Lei et al., 1999; Menguc et al., 2007; Senge et al., 1994; Slater and Narver, 1995; Tushman and Nadler, 1986).

More specifically, transformational leadership fuels organizational learning by promoting intellectual stimulation and providing inspirational motivation and self-confidence among organization members (Coad and Berry, 1998). The transformational leader will be a catalyst, a mentor, a facilitator and a trainer in organizational learning. He or she encourages shared mental models in technological organizations that favor continuous learning and facilitate technological learning and the use of new technologies (Senge et al., 1994).

Transformational leadership generates greater consciousness and acceptance of the purpose and mission of the organization and fosters a shared vision, reorienting the training and construction of work teams. This leadership style also allows the leader to commit him- or herself openly to learning, to become its driving force, and to provide whatever is needed to overcome internal skepticism and external difficulties to establish learning within the organization (Wick and Leon, 1995).

The influence of transformational leadership on communication and the influence of communication on organizational learning produce an indirect effect of transformational leadership on organizational learning through communication (Argyris and Schön, 1996; Lei et al., 1999; Schein, 1993; Senge et al., 1994). On the basis of these arguments, the capability for transformational leadership is one of the most important means of developing organizational learning in organizations (Maani and Benton, 1999; Slater and Narver, 1995).

H1. A positive association exists between transformational leadership and organizational learning.

The strategic literature highlights leadership style as an especially important influence on organizational innovation (Kanter, 1983; McDonough, 2000; Van de Ven, 1986). Broad consensus currently affirms that a collaborative and participatory leadership style (transformational) is more likely to encourage innovation within the organization (Kanter, 1983) than are transactional styles of leadership (Manz et al., 1989). Managers' perceptions of their role in their organizations strongly influence the capability to promote such leadership in an organization. 
Several features of transformational leadership are relevant for firm innovation (Gumusluoglu and İlsev, 2009; Lian Shao, 2006). Transformational leaders have an interactive vision; they pay maximum attention to fostering effective communication and sharing values (Adair, 1990) and encouraging an appropriate environment for innovative teams (Tushman and Nadler, 1986). They support collective processes of organizational learning (Manz et al., 1989), reciprocal trust between organization members and leaders (Scott and Bruce, 1994), and favorable attitudes toward proactivity, risk (Lefebvre and Lefebvre, 1992) and creativity (Tierney et al., 1999). All of these features together enable a better understanding of the strong relationships between transformational leadership and the factors positively influencing organizational innovation (Kanter, 1983).

Finally, transformational leaders have charisma, provide inspiration, and promote intellectual stimulation. These characteristics encourage communication processes and organizational learning that enable organizations to be more innovative (Bass, 1999; Bass and Avolio, 2000; Conger, 1999). Transformational leadership thus influences innovation indirectly through the communication process (García-Morales, 2004; Tushman and Nadler, 1986) and the process of organizational knowledge creation (Cohen and Levinthal, 1990; Nonaka and Takeuchi, 1995; Senge et al., 1994). Further, transformational leadership has an indirect effect on innovation based on the presence of both strategic factors (communication and organizational learning) and the interrelation between them (Lei et al., 1999; Schein, 1993; Senge, 1990).

H2. A positive association exists between transformational leadership and organizational innovation.

\subsection{The influence of organizational learning on organizational innovation}

The extensive and diverse literature on organizational innovation has received important contributions from works on organizational learning in the last decade. Much of this research observes a positive relationship between organizational learning and organizational innovation (e.g., Calantone et al., 2002; Tushman and Nadler, 1986). Different types of organizational learning (adaptive/generative) and innovation (incremental/radical) have a close, positive connection (Forrester, 2000). The deeper innovation reaches, the greater the degree of learning required.

Thus, the more innovative the products, services or methods, the greater the degree of critical capacity, skill and new and relevant knowledge necessary (Senge et al., 1994). The process of creating organizational knowledge, which draws new knowledge from existing (organizational learning), is the cornerstone of innovative activities. Organizational knowledge creation is the process that strengthens innovation, not knowledge in itself (Nonaka and Takeuchi, 1995). Further, organizational innovation depends on the organization's knowledge base, and organizational learning in turn promotes this knowledge base (Cohen and Levinthal, 1990).

An increasing number of firms analyze organizational innovation as an organizational learning process or apply organizational learning models to specific aspects of the organizational innovation process (MERIT, 1992). Organizational learning supports creativity (e.g., Sánchez and Mahoney, 1996; Yli-Renko et al., 2001), inspires new 
knowledge and ideas (e.g., Damanpour, 1991), increases ability to understand and apply these ideas (e.g., Damanpour, 1991), favors organizational intelligence and (with the organization's culture) forms a background for orientation to organizational innovation.

An organization committed to learning increases its organizational innovative capability because the organization is less likely to miss the opportunities that emerging market demand creates. Such organizations have the ability and knowledge to anticipate and understand customer needs, possess more and better state-of-the art technology, and use that technology to innovate. They also have a stronger capacity to understand rivals' strengths and weaknesses and thus to learn from their successes and their failures and to generate greater innovative capability than competitors (Calantone et al., 2002).

These ideas have recently begun to receive some empirical attention. Hurley and Hult (1998) focus on a large agency of the U.S. federal government to show a positive association between organizational innovation and a culture that emphasizes adaptation, innovation, and learning. Meeus et al. (2001) analyze a sample of innovator firms to show that more complex innovative activities urge firms to coordinate and exchange information between users and producers, which implies strong interactive learning.

H3. A positive association exits between organizational learning and organizational innovation.

\subsection{The influence of organizational learning and organizational innovation on organizational performance}

The literature emphasizes the importance of organizational learning for a company's survival and effective performance (Argyris and Schön, 1996; Fiol and Lyles, 1985; Inkpen and Crossan, 1995; Senge, 1990). However, empirical analysis of this relationship has been limited, due to various difficulties, such as ambiguity or the time delay between the two (today's learning will affect tomorrow's performance) and the possibility that exogenous factors disguise the results of learning. Research should analyze the influence of organizational learning on performance in technological firms empirically, but little knowledge is available concerning the mechanisms that transform organizational learning into performance (Inkpen and Crossan, 1995; Snyder and Cummings, 1998).

To assert that an increase in organizational learning always leads to growth in organizational performance is erroneous, since learning may not always improve an organization's results (Hoopes and Postrel, 1999; Inkpen and Crossan, 1995; Tsang, 1997). Nonetheless, generally speaking, organizational learning has a positive influence on performance improvements. This positive influence normally occurs in both technological companies and manufacturing firms (Argyris and Schön, 1996; Decarolis and Deeds, 1999; Fiol and Lyles, 1985; Senge, 1990). Firms that show a greater breadth, depth, and speed of organizational learning have higher performance levels (Hurley and Hult, 1998). The primary aim of organizational learning is to enhance performance quality and quantity, allowing the firm to increase and improve sales; to achieve more support; and to create, maintain and enlarge its customer base. Further, organizations that learn and learn quickly increase strategic capability, enabling them to sustain a position of competitive advantage and improve their results. These attitudes, behaviors, and strategies of organizational learning will guide organizations to superior long-term performance. 
Organizations that encourage the learning spirit sacrifice (to some extent) immediate performance to achieve future performance, since immediate performance is due to the organizational learning drawn from yesterday, while future performance will be the product of today's learning process (Guns, 1996; Senge, 1990).

H4. A positive association exists between organizational learning and organizational performance.

Different theories reveal that organizational innovation is essential for better performance. According to marketing theories, organizations that concentrate on speed of innovation gain a greater market share, which produces high income and high profitability. Strategic theories stress that organizations that adopt an innovation first are able to create isolation mechanisms. Because knowledge of the innovation is not available to competitors, these mechanisms protect profit margins, enabling the organization to gain important benefits. Likewise, the theory of resources and capabilities maintains that the capabilities, resources and technologies needed to adopt the innovation make external imitation more difficult and allow firms to sustain their competitive advantages and obtain greater organizational performance (Irwin et al., 1998; Lengnick-Hall, 1992; Lieberman and Montgomery, 1988).

Thus, a positive link exists between organizational innovation and organizational performance (Zahra et al., 2000; Zaltman et al., 1973), or between different aspects of organizational innovation (e.g., innovation design or speed, flexibility) and organizational performance (Calantone et al., 2002; Capron, 1999; Danneels and Kleinschmidt, 2001; Gopalakrishnan, 2000; Hall and Bagchi-Sen, 2000). The innovation literature also includes various empirical studies supporting this relationship, as do various works that use econometric methods to demonstrate the relationship empirically (Lööf and Heshmati, 2002).

The more valuable, imperfectly imitable and rare innovations (e.g., technological) are, the higher performance will be (Irwin et al., 1998). Organizations with greater innovation will achieve a better response from the environment, obtaining more easily the capabilities needed to increase organizational performance and consolidate a sustainable competitive advantage (Calantone et al., 2002; Hurley and Hult, 1998; Zaltman et al., 1973). Not promoting innovative projects and activities will have a negative effect on productivity and organizational performance (Lööf and Heshmati, 2002). Innovation as a dimension of intrapreneurship has a direct influence on organizational performance (Hudges and Morgan, 2007; Zahra et al., 2000).

H5. A positive association exists between organizational innovation and organizational performance.

\section{Method}

This section presents the sample used, the research methodology and the statistical analysis.

\subsection{Sample and procedures}


The population for this study consists of Spanish firms from the automotive and chemical sectors. The research uses the AMADEUS (2004) database, choosing all Spanish firms with National Classification of Economic Activities (CNAE-93 Review 1) 24, the chemical industry, and CNAE 34 and 35, the manufacturing of transportation materials. The authors then purified the information to eliminate possible duplications caused by the inclusion of affiliates in the database. The final study population consists of 5163 firms.

The study focuses on the automotive and chemical sectors because they represent a greater percentage, billing volume and employment volume of the Spanish economy. Further, use of a sample of firms located in a relatively homogeneous geographic, economic, political, sociocultural, technological and legal space minimizes the impact of variables that cannot be controlled in the empirical research (Adler, 1983). The Spanish market is relatively well developed and wholly integrated in the European Union and has had a slightly better rate of growth in recent years than the European market overall. However, Spain is in a geographical area that has received relatively little attention from organizational researchers.

Drawing on knowledge about key dimensions of this investigation, previous contacts with interested CEOs and scholars, and new interviews with CEOs and academics interested in the topic and familiar with the chemical and automotive sectors, the authors developed a structured questionnaire to investigate how organizations face these issues. The study omits the responses of the interviewees from this first stage in the subsequent analysis of the survey data.

The study uses CEOs as the key informants, since they receive information from a wide range of departments and are therefore a very valuable source for evaluating the different variables of the organization. CEOs also play a major role in informing and molding the variables under study by determining the types of behavior that are expected and supported (Baer and Frese, 2003). Although the management process may involve numerous actors, the CEO is ultimately responsible for plotting the organization's direction and plans, as well as for guiding the actions carried out to achieve them (Porac and Thomas, 1990; Westphal and Fredickson, 2001). This study uses the same types of informant to maintain the level of influence among the organizations constant, increasing the validity of the variables' measurements (Glick, 1985). The cover letter requested that CEOs not answer the questionnaire unless they could directly observe or had knowledge of the variables in question (Kozlowski and Klein, 2000). This condition decreased the percentage of responses but increased the reliability and validity of the questionnaires received.

Mailed surveys were sent to the CEOs of the 1000 randomly selected organizations with a cover letter (they did not replace the 36 questionnaires returned due to unknown address with others). The selection procedure involved stratified random sampling with two levels of stratification (size and sector). This mailing method reached a greater number of firms at a lower cost than travelling to the specific firm to perform personal interviews, exercised less pressure for an immediate response, and provided the interviewees with a greater feeling of autonomy. The cover letter explained the goal of the study, offered recipients the option of receiving the results on completion of the study, indicated the basic ethical principles of the research, and reiterated the necessity that the person chosen answer the questionnaire, even at the cost of receiving fewer responses. 
To reduce possible desirability bias, the cover letter promised to keep all individual responses completely confidential, confirmed that the analysis would be restricted to an aggregate level for the publications that would prevent the identification of any individual or organization, and arranged for all completed questionnaires to be returned directly by mail instead of being routed through the organization (Bueno et al., 2010; Lechner et al., 2010; Tsai and Ghoshal, 1998).

Each CEO who had not yet responded received two reminders by mail. 170 CEOs finally answered the questionnaire, but because of missing values the research includes only 168 questionnaires. The response rate is $17.43 \%$ (Table 1).

\section{Table 1}

Technical details of the research.

\begin{tabular}{ll}
\hline Sectors & Chemical and automotive sectors \\
Geographical location & Spain \\
Methodology & Structured questionnaire \\
Procedure & Stratified sample with proportional \\
& allocation (size, sector) \\
Universe of population & 5163 firms \\
Sample (response) size & $964(168)$ firms \\
Sample error & $3.47 \%$ \\
Confidence level & $95 \%, p-q=0.50 ; Z=1.96$ \\
\hline
\end{tabular}

To eliminate the possibility of non-response bias, the authors compared the characteristics of the respondents and of early and late responders in the sample (Armstrong and Overton, 1977). No significant differences exist based on the size or type of business. Furthermore, since the same survey instrument collected all measures, the study tested for the possibility of common method bias using Harman's one-factor test (e.g., Konrad and Linnehan, 1995; Scott and Bruce, 1994). A principal components factor analysis of the questionnaire measurement items yielded four factors with eigenvalues greater than 1.0, which account for $70 \%$ of the total variance, identifying several factors, as opposed to one single factor. Since the first factor does not account for the majority of the variance, a substantial amount of common method variance does not appear to be present (Podsakoff and Organ, 1986).

\subsection{Measures}

The use of constructs plays an important role in designing a survey instrument in management research. In any research concerning behavioral elements, no device using a single metric unit can measure precisely, and researchers usually employ two or more measures to gauge a construct or scale. Given that developing new constructs or scales of measurement is a complex task, wherever possible this study uses pre-tested constructs from past empirical studies to ensure their validity and reliability.

\subsubsection{Transformational leadership}

The study uses the scale of four items developed by McColl-Kennedy and Anderson (2002). These items are duly adapted to the present study. As in other similar studies, the 
CEOs indicated their perceptions about the behavior of transformational leadership in the organization (e.g., Fein et al., 2010; Sarros et al., 2008). The authors used a confirmatory factor analysis to validate a Likert-type 7-point scale (1 "totally disagree," 7 "totally agree"), which required deletion of Item 1 ( $\chi 22=7.23$, Normed Fit Index [NFI] =.99, NonNormed Fit Index [NNFI]=.99, Goodness of Fit Index [GFI] =.99, Comparative Fit Index $[\mathrm{CFI}]=.99$, Incremental Fit Index $[\mathrm{IFI}]=.99$ ). The scale is unidimensional. This procedure allowed selection of three items (see Appendix A) with high validity and reliability $(\alpha=.91)$. The study also chose one subordinate in the organization to respond to the questionnaire to confirm the relationship between the self-reports of the CEOs and those of their subordinates. The items asked the respondents to evaluate whether their CEO demonstrated the leadership behavior described. For the responses received, the authors confirm the absence of significant mean differences between the two groups of respondents (based on a t test) in the data on transformational leadership used in this research $(\mathrm{t}(\mathrm{item} 2)=1.26$ n.s.; $\mathrm{t}(\mathrm{item} 3)=0.85$ n.s.; $\mathrm{t}(\mathrm{item} 4)=0.23$ n.s. $)$, and the results from the correlation analysis show strong relationships between the CEOs' responses and those of their subordinates with respect to transformational leadership (ranging from 0.71 to $0.81, \mathrm{pb} .01$ ). These results provide an added degree of confidence in the current results. Since the authors find no significant differences and prefer not to decrease the sample size, the study uses the CEO's responses.

\subsubsection{Organizational learning}

The study uses a scale of four items developed by Aragón et al. (2007) and García Morales, Lloréns Montes and Verdú Jover (2006, 2008a) to measure organizational learning (1 "totally disagree", 7 "totally agree"). These items are duly adapted to the present study. The authors develop a confirmatory factor analysis to validate the scales $(\chi 22=3.90, \mathrm{NFI}=.99, \mathrm{NNFI}=.99, \mathrm{GFI}=.99, \mathrm{CFI}=.99, \mathrm{IFI}=.99)$ and show that the scale is unidimensional and has adequate validity and reliability $(\alpha=.71)$.

\subsubsection{Organizational innovation}

Numerous researchers analyze organizational innovation using reliable valid scales that enable its measurement. This study takes the scale from Antoncic and Hisrich (2001), which uses a Likert-type 7-point scale ( 1 "totally disagree," 7 "totally agree"), requiring deletion of Item $8(\chi 227=76.63, \mathrm{NFI}=.98, \mathrm{NNFI}=.99, \mathrm{GFI}=.99, \mathrm{CFI}=.98$, IFI =.99). The scale is unidimensional. This procedure yields selection of nine items (see Appendix A) with high validity and reliability $(\alpha=.94)$.

\subsubsection{Organizational performance}

Based on a review of how different works of strategic research measure performance, the authors use the scale of five items developed by Murray and Kotabe (1999). The use of scales to evaluate performance relative to the main competitors is one of the most widelyaccepted practices in recent studies (Choi et al., 2008; Deshpandé et al., 1993; Douglas and Judge, 2001; Vorhies et al., 1999). Many researchers use managers' subjective perceptions to measure beneficial outcomes for firms. Others prefer objective data, such as return on assets.

A wide range of literature establishes a high correlation and concurrent validity between objective and subjective data on performance, implying that both are valid when 
calculating a firm's performance (Homburg et al., 1999; Venkatraman and Ramanujam, 1986). This study includes questions involving both types of assessment in the interviews, but the CEOs were more open to offering general views than precise quantitative data.

When possible, the study estimates the correlation between objective and subjective data, and these are high and significant. The study includes a confirmatory factor analysis to validate the scales $(\chi 25=22.32, \mathrm{NFI}=.97, \mathrm{NNFI}=.96, \mathrm{GFI}=.99, \mathrm{CFI}=.98$, IFI $=.98)$ and show that the scale is unidimensional and has high reliability $(\alpha=.87)$. A Likert-type 7point scale (1 "Much worse than my competitors," 7 "Much better than my competitors") asks about the organization's performance as compared with that of its most direct competitors.

\subsection{Model and analysis}

Given the existence of an exogenous latent variable (transformational leadership $[\xi]$ ), a first-grade endogenous latent variable (organizational learning [ $\eta 1]$ ) and second-grade endogenous latent variables (organizational innovation [ $\eta 1]$ and organizational performance $[\eta 32])$, the study analyzes the data using structural equations modeling (LISREL 8.30 program) to establish causal relationships between these variables. This procedure translates the theoretical construction into mathematical models in order subsequently to estimate and evaluate them empirically (Jöreskog and Sörbom, 1996).

Fig. 1 presents the theoretical model. The findings give the hypotheses concrete form. The study uses a recursive non-saturated model. Structural equation modeling takes into account errors in measurement, variables with multiple indicators and multiple-group comparisons (Koufteros et al., 2009).

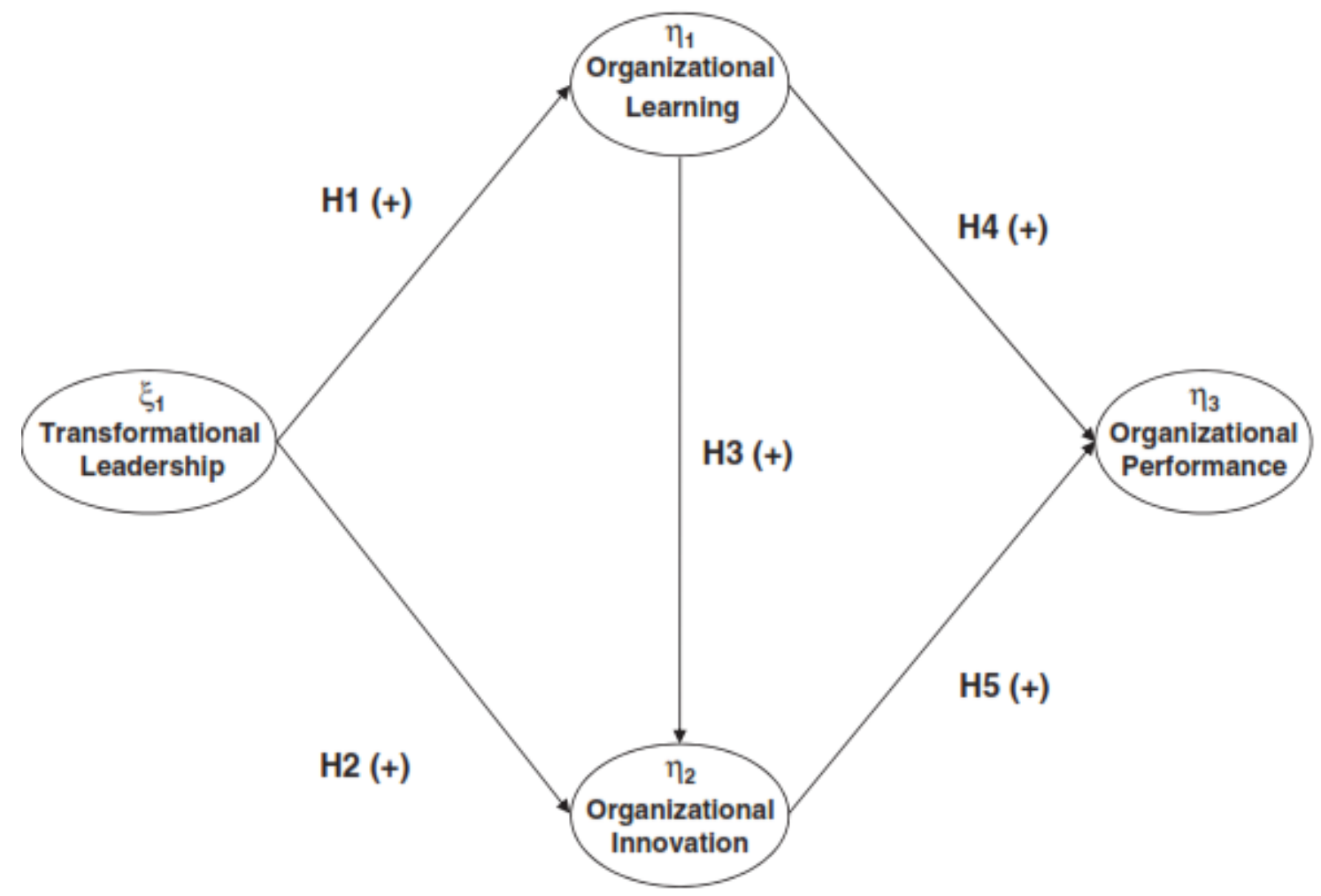

Fig. 1. Hypothesized model. 


\section{Results}

This section presents the main research results. First, Table 2 shows the means and standard deviations as well as the inter-factor correlation matrix for the study variables. Significant and positive correlations exist among transformational leadership, organizational learning, organizational innovation and organizational performance. Initially, a series of regressions (Table 3) shows the direct effects analyzed in the research and uses a series of tests (e.g., tolerance, variance inflation factor) to confirm the nonpresence of multicolinearity (Hair et al., 1999).

Table 2

Means, standard deviations and correlations.

\begin{tabular}{lcrllll}
\hline Variable & Mean & S.D. & \multicolumn{1}{l}{ 1 } & \multicolumn{1}{l}{3} & 3 & 4 \\
\hline 1. Transformational leadership & 5.18 & 1.30 & 1.00 & & & \\
2. Organizational learning & 5.54 & .96 & $.59^{* * *}$ & 1.00 & & \\
3. Organizational innovation & 4.79 & 1.26 & $.49^{* * *}$ & $.40^{* * *}$ & 1.00 & \\
4. Organizational performance & 4.54 & .94 & $.39^{* * *}$ & $.36^{* * *}$ & $.37^{* * *}$ & 1.00 \\
\hline Note: ${ }^{* * *} p<.001$ (two-tailed). $\mathrm{n}=168$. & & & & &
\end{tabular}

Table 3

\begin{tabular}{|c|c|c|c|c|c|c|}
\hline \multirow{2}{*}{$\begin{array}{l}\text { Dependent variables } \\
\text { Independent variables }\end{array}$} & \multicolumn{2}{|l|}{ Organizational learning } & \multicolumn{2}{|l|}{ Organizational innovation } & \multicolumn{2}{|c|}{ Organizational performance } \\
\hline & Coefficients (t statistics) & TOL (VIF) & Coefficients (t statistics) & TOL (VIF) & Coefficients (t statistics) & TOL (VIF) \\
\hline Constant & $3.24^{* * *}(12.88)$ & & $1.62 * *(3.16)$ & & $2.18^{* * *}(5.31)$ & \\
\hline Transformational leadership & $0.59^{\cdots \cdots}(9.43)$ & $1.00(1.00)$ & $0.39 \cdots(4.59)$ & $0.64(1.56)$ & & \\
\hline Organizational learning & & & $0.16^{*}(1.97)$ & $0.64(1.56)$ & $0.27^{* *}(3.42)$ & $0.85(1.17)$ \\
\hline Organizational innovation & & & & & $0.26^{* *}(3.29)$ & $0.85(1.17)$ \\
\hline $\mathrm{R}^{2}$ & 0.35 & & 0.25 & & 0.19 & \\
\hline Adjusted $R^{2}$ & 0.35 & & 0.24 & & 0.18 & \\
\hline $\mathrm{F}$ & $89.01^{\ldots *}$ & & $27.20^{\ldots *}$ & & $18.37^{* \cdots}$ & \\
\hline Standard Error & 0.77 & & 1.09 & & 0.84 & \\
\hline
\end{tabular}

Note: " $p<05, * * p<01 ; * * p<001$ (two-tailed); TOL = Tolerance; VIF = Variance Inflation Factor.

Second, the study performs structural equations modeling to estimate direct and indirect effects using LISREL with the correlation matrix as input. This type of analysis has the advantage of correcting for unreliability of measures and also provides information on the direct and indirect paths between multiple constructs after controlling for potentially confounding variables. Fig. 2 shows the standardized structural coefficients. The magnitude of the coefficients reflects the relative importance of the variables.

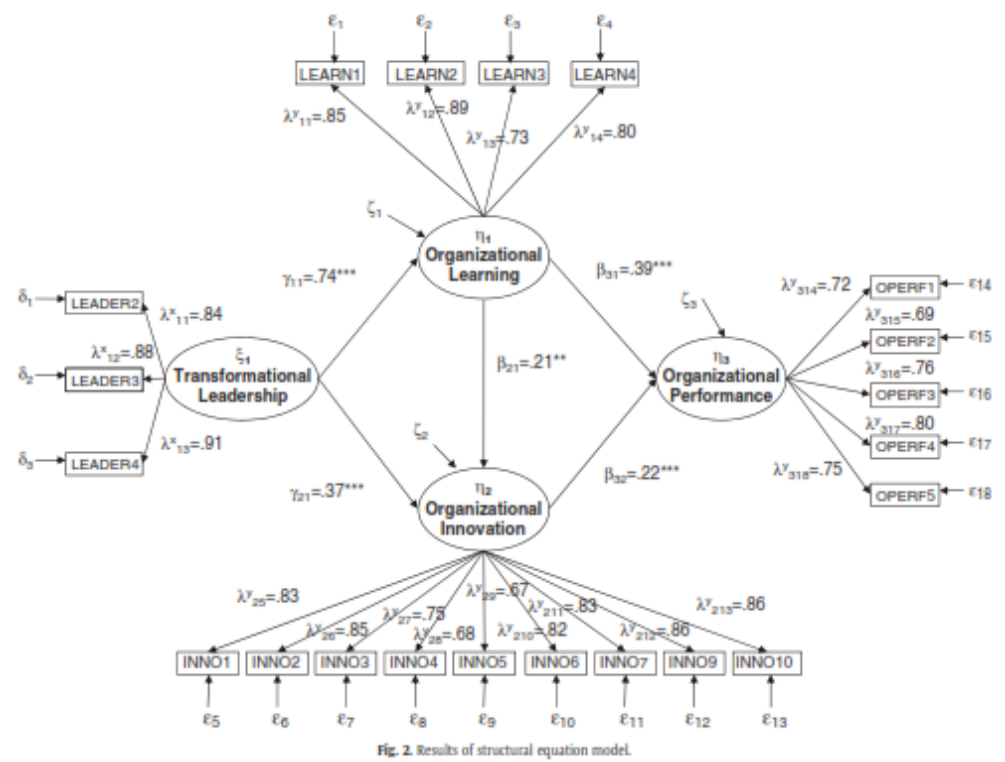


For the quality of the measurement model for the sample, the constructs display satisfactory levels of reliability, since the composite reliabilities range from 0.86 to 0.94 and the shared variance coefficients from 0.56 to 0.77 (Table 4). The authors conclude convergent validity from examination of both the significance of the factor loadings and the shared variance. The amount of variance shared or captured by a construct should be greater than the amount of measurement error (shared varianceN0.50).

\begin{tabular}{|c|c|c|c|c|c|}
\hline \multirow[t]{2}{*}{ Variable } & \multirow[t]{2}{*}{ Item } & \multirow[t]{2}{*}{ Parameter } & \multicolumn{3}{|c|}{ Validity, reliability and internal consistency } \\
\hline & & & $\overline{\lambda^{*}}$ & $R^{2}$ & A. M. \\
\hline \multirow[t]{3}{*}{ Transformational leadership } & LEADER2 & $\lambda_{11}^{x}$ & 0.84 (f.p.) & 0.71 & $\alpha=0.91$ C. R. $=0.91$ S. V. $=0.77$ \\
\hline & LEADER3 & $\lambda_{12}^{x}$ & $0.88^{* * *}(15.36)$ & 0.77 & \\
\hline & LEADER4 & $\lambda_{13}^{x}$ & $0.91^{\cdots *}(15.71)$ & 0.82 & \\
\hline \multirow{4}{*}{ Organizational learning } & LEARN1 & $\mathrm{Ay}_{1}$ & 0.85 (f.p.) & 0.73 & $\alpha=0.71$ C. R. $=0.90$ S. V. $=0.70$ \\
\hline & LEARN2 & $\mathrm{Al}_{12}^{y_{2}}$ & $0.89^{* *}(15.06)$ & 0.79 & \\
\hline & LEARN3 & $\lambda_{13}^{y_{13}}$ & $0.73^{* *}(14.13)$ & 0.53 & \\
\hline & LEARN4 & $\mathrm{N}_{4}$ & $0.83^{* *}(14.41)$ & 0.79 & \\
\hline \multirow[t]{9}{*}{ Organizational innovation } & INNO1 & $\mathrm{Ay}_{0}$ & 0.83 (f.p.) & 0.69 & $\alpha=0.94$ C. R. $=0.94$ S. V. $=0.64$ \\
\hline & INNO2 & $\lambda_{20}^{y}$ & $0.85^{* * *}(18.14)$ & 0.73 & \\
\hline & INNO3 & $\mathrm{N}_{27}^{20}$ & $0.75^{* * *}(17.19)$ & 0.57 & \\
\hline & INNO4 & $\mathrm{Al}_{28}^{2}$ & $0.68^{* * *}(16.42)$ & 0.46 & \\
\hline & INNO5 & $\lambda_{29}^{18}$ & $0.67^{* *}(16.32)$ & 0.45 & \\
\hline & INNO6 & $\lambda_{2 y}^{3}$ & $0.82 * *(17.90)$ & 0.68 & \\
\hline & INNO7 & $x_{211}^{2}$ & $0.83^{* *}(18.05)$ & 0.69 & \\
\hline & INNO9 & $x_{212}^{y}$ & $0.86 * *(18.30)$ & 0.75 & \\
\hline & INNO10 & $\lambda_{213}^{y}$ & $0.86^{* *}(18.23)$ & 0.74 & \\
\hline \multirow{5}{*}{ Organizational performance } & OPERF1 & $\lambda_{y 14}^{213}$ & 0.72 (p.f.) & 0.52 & $\alpha=0.87$ C. R. $=0.86$ S. V. $=0.56$ \\
\hline & OPERF2 & $\lambda_{313}^{3}$ & $0.69^{* *}(12.24)$ & 0.48 & \\
\hline & OPERF3 & $\lambda_{10}^{y}$ & $0.76^{* *}(12.52)$ & 0.58 & \\
\hline & OPERF4 & $\lambda_{317}^{310}$ & $0.80^{* \cdots}(12.16)$ & 0.64 & \\
\hline & OPERF5 & $\begin{array}{l}3 y_{18}^{317} \\
\lambda_{318}\end{array}$ & $0.75^{* * *}(12.43)$ & 0.57 & \\
\hline
\end{tabular}

Note: $\lambda^{*}=$ Standardized Structural Coefficient; $\mathrm{R}^{2}=$ Reliability; $\alpha=$ Alpha Cronbach; C. $\mathrm{R}$ = Compound Reliability; S. V. = Shared Variance; f. p. = fixed parameter; A. M. = Adjustment Measurement; $\cdots p<$.001(two-tailed).

All multi-item constructs meet this criterion; each loading $(\lambda)$ is significantly related to its underlying factor (t-values>12.16) in support of convergent validity. To assess discriminate validity, the authors perform a series of chi-square difference tests on the factor correlations among all the constructs (Anderson and Gerbin, 1988). The study follows this procedure for each pair of latent variables, constraining the estimated correlation parameter between them to 1.0 and then performing a chi-square difference test on the values obtained for the constrained and unconstrained models (Anderson and Gerbin, 1988). The resulting significant differences in chi-square indicate absence of perfect correlation between the constructs and thus discriminant validity.

The overall fit measures, multiple squared correlation coefficients of the variables (R2s), and signs and significance levels of the path coefficients indicate that the model fits the data well $(\chi=559.88, \mathrm{pN} .001 ; \chi 2$ ratio=3.04; NFI=.97; NNFI=.99; GFI $=.98$, CFI $=.99$, IFI $=.99$, PGFI=.78). The hypothesized model is a significantly better fit than the null model $(\chi 2210=5409.25$, pN.001; $\Delta \chi \mathrm{pN} .001)$. All modification indices for the beta pathways between major variables are small, suggesting that adding additional paths would not significantly improve the fit. The residuals of the covariances are also small and center around zero.

Findings from the standardized parameter estimates (Table 5) show that transformational leadership is closely related to and affects organizational learning $(\gamma 11=.74$, pb.001, $\mathrm{R} 2=.55)$ and organizational innovation $(\gamma 21=.37$, p.001), as predicted in Hypotheses 1 and 2, respectively. Furthermore, the results show an indirect effect $(.15, \mathrm{pb} .01)$ of transformational leadership on organizational innovation by organizational learning (.74 $\times .21$; e.g., Bollen, 1989 for calculation rules). The global influence of transformational leadership on organizational innovation is thus 0.52 (pb.001). Comparing the magnitudes of these effects indicates that the effect of organizational learning on organizational 
innovation is larger than the total effect of transformational leadership on organizational innovation. Globally, the model explains organizational innovation well ( $R(\beta 2=.29)$.

\begin{tabular}{|c|c|c|c|c|c|c|c|c|}
\hline Effect from & To & & Direct Effects a & $t$ & Indirect Effects ${ }^{2}$ & $t$ & Total Effects ${ }^{2}$ & $t$ \\
\hline Transformational leadership & $\rightarrow$ & Organizational learning & $0.74^{* * *}$ & 10.54 & & & $0.74^{4 * *}$ & 10.54 \\
\hline Transformational leadership & $\rightarrow$ & Organizational innovation & $0.37^{* * *}$ & 4.17 & $0.15^{* *}$ & 2.67 & $0.52^{* * *}$ & 10.76 \\
\hline Transformational leadership & $\rightarrow$ & Organizational performance & & & $0.41^{\cdots \cdots}$ & 9.50 & $0.41^{* \cdots}$ & 9.50 \\
\hline Organizational learning & $\rightarrow$ & Organizational innovation & $0.21^{*}$ & 2.47 & & & $0.21^{*}$ & 2.47 \\
\hline Organizational learning & $\rightarrow$ & Organizational performance & $0.39^{* * *}$ & 7.05 & $0.04^{* *}$ & 2.65 & $0.43^{* * *}$ & 7.37 \\
\hline Organizational innovation & $\rightarrow$ & Organizational performance & $0.22 * *$ & 5.47 & & & $0.22 * * *$ & 5.47 \\
\hline Goodness of fit statistics & \multicolumn{8}{|c|}{$\begin{array}{l}\chi_{184}^{2}=578.36(P>0.01) \mathrm{CFl}=0.98 \mathrm{AGFl}=0.98 \mathrm{ECVI}=4.48 \mathrm{AIC}=6042.74 \mathrm{CAIC}=6127.10 \mathrm{NFI}=0.98 \mathrm{NNFl}=0.99 \mathrm{IFl}=0.99 \mathrm{PCFl}=0.78 \\
\mathrm{PNFI}=0.86 \mathrm{NCP}=394.36 \mathrm{RFI}=0.97 \mathrm{CFI}=0.99\end{array}$} \\
\hline
\end{tabular}

Organizational learning influences organizational innovation $=.21$, pb.01), supporting H3. Finally, the study finds a significant relationship between organizational performance and both organizational learning $(\beta 21=.39$, pb.001) and organizational innovation ( $\beta 3231=.22$, pb.001), supporting H4 and H5, respectively.

Results also show an indirect effect (.04, pb.01) of organizational learning on organizational performance by organizational innovation $(.21 \times .22)$. The global influence of organizational learning on organizational performance is thus .43 (pb.001). Comparing the magnitudes of these effects indicates that the effect of organizational learning on organizational performance is larger than the total effect of organizational innovation on organizational performance. Globally, the model explains organizational innovation well $(\mathrm{R} 2=.29)$. In addition to these effects, the study shows indirect effects of transformational leadership on organizational performance (Table 5).

\section{Conclusions and future research}

Organizations need transformational leadership to improve their performance in changing real-life business environments. This research contributes to such performance improvement by showing the strategic role of organizational learning and organizational innovation. Management of these variables gives rise to values within the organization that are difficult to copy. Specifically, the results support all of the hypotheses, showing that a management style of transformational leadership through organizational learning and innovation simultaneously influences organizational performance.

First, the research shows a positive relation between transformational leadership and organizational learning and innovation. This leadership style analyzes, modifies, and drives systems, designing them to share and transfer knowledge through the process of organizational learning (Lei et al., 1999; Senge, 1990). Thus, transformational leadership is committed to and propels organizational learning (Senge, 1990; Swieringa and Wierdsma, 1992), making available everything necessary to overcome the obstacles that might impede this learning (Wick and Leon, 1995). Organizational learning seeks to establish a path for professional development to acquire aptitudes or competencies that give sustainable advantage through innovation (Senge et al., 1994).

The study also verifies a positive relation between transformational leadership and innovation directly and indirectly through the construction of competencies focused on learning to minimize the cost of internal change (Lei et al., 1999; Slater and Narver, 1995). The results support the importance of transformational leadership in generating innovation (McDonough, 2000), an especially appealing finding that supports 
characterizing transformational leadership as more concerned with collective decisions, collective goals, and the generation of capabilities than is transactional leadership.

Third, the study demonstrates empirically a positive relation between organizational learning and innovation. The innovative organization learns and knows how to make and keep itself competent. Through learning, the organization can change its behavior and thus renew and reinvent its technology and production to avoid falling into stagnation and to permit organizational innovation. Different organizations will find themselves in different states of evolution in learning. Organizational learning prevents stagnation and encourages continuous innovation (Bessant and Buckingham, 1993; Glynn, 1996; Thomas et al., 2001).

Fourth and finally, the study verifies empirically a positive relationship between more organizational learning and innovation and organizational performance. Organizations' complexes of essential production and technology competences or resources and capacities sustain the sources for achieving sustainable competitive advantages. Each organization should analyze all of its production and technological resources, the resources that enable achievement of a better competitive position on the market. The organization should also develop specific capacities and essential competences to face the changes in production and technology in its environment. Thus, the organization acquires a dynamic and proactive vision that improves organizational performance, generating its own resources and capacities that are unique, valuable, hard to replace, and difficult to imitate. Two main variables that determine organizational performance are thus organizational learning and innovation, both of which have positive causal effects. These two dynamic capabilities are strategic (Calantone et al., 2002; Danneels and Kleinschmidt, 2001; Hurley and Hult, 1998; Zahra et al., 2000).

This investigation has several limitations. First, the study measures the variables based on the CEOs' managerial perceptions (single respondents), which involve a certain degree of subjectivity. The respondents are CEOs of firms because their knowledge about these strategic variables is more comprehensive (e.g., Shortell and Zajac, 1990). In the absence of published data on these variables and alternative sources of comparative data, the study follows the methods used in the past by other studies (e.g., Egri and Herman, 2000; García Morales et al., 2008a,1 b; García Morales et al., 2008b; Nandakumar et al., 2010; Sarros et al., 2008).

However, the study here includes contrasting some variables with either objective data (e.g., organizational performance) or the response of the subordinates (e.g., transformational leadership) and finds no significant mean differences between the two types of measures. Further, the results from the correlation analysis show close relationships.

A second limitation of this study concerns the measures of transformational leadership. Other investigations also survey CEOs or managers (e.g., Egri and Herman, 2000; Fein et al., 2010; García Morales et al., 2008a; Sarros et al., 2008). Although existing evidence suggests that self-reports of leadership are valid measures (e.g., Yukl and Van Fleet, 1991), interviewing and administering questionnaires to all other organizational members (and not only to subordinates) would have been preferable to verify leaders' self-report of their behavior (e.g., Egri and Herman, 2000; Sarros et al., 2008). One could also use different scales to measure transformational leadership. 
Third, although Harman's one-factor test and other method tests do not identify common method variance as a problem, this bias may still be present (Konrad and Linnehan, 1995; Podsakoff and Organ, 1986). While Spector (2006) argues against assuming that the use of a single method automatically introduces systematic bias, studies recommend that future research gather measures of independent and dependent variables from varied data sources (e.g., more subordinates' ratings of transformational leadership and objective measures of organizational innovation) to minimize the effects of any response bias (Podsakoff et al., 2003).

Fourth, the study data are cross-sectional, hindering examination of the evolution of the variables in this study. This aspect is of particular interest given the dynamic nature of some variables. Although the authors test the most plausible directions for the pathways in the study model, only longitudinal research can assess the direction of causality of the relationship and detect possible reciprocal processes. The authors have tried to temper this limitation through attention to theoretical arguments by rationalizing the analyzed relationships and integrating temporal considerations into measurement of the variables (Hair et al., 1999). Fifth, future studies should analyze a larger sample, preferably in more than one country and in other sectors.

Finally, the model only analyzes the relation between transformational leadership and organizational performance through organizational learning and organizational innovation. Although selected variables explain an acceptable amount of variance in organizational performance, research could analyze other intermediate constructs, such as shared vision, teamwork or technology (Senge et al., 1994). Future studies might also examine other consequences of introducing learning and innovation processes in organizations (e.g., quality improvement, staff satisfaction, and improvements in relational capacity). The homogeneous geographical context examined here limits the influence of external factors, but future research might well explicitly integrate the influence of external factors (Aragon Correa and Sharma, 2003).

\section{Acknowledgements}

The authors gratefully acknowledge the cooperation and financial support provided by the Spanish Ministry of Education (Project ECO2009-09241) and the Andalusian Regional Government (Excellence Research Project P08SEJ-4057). Comments by Matías-Reche, University of Granada and Verdú-Jover, University of Miguel Hernandez (Elche) on an earlier draft were helpful in revising this paper. The authors alone are responsible for all limitations and errors that may relate to the study and the paper.

\section{Appendix A}

* Transformational Leadership

2. Transmits the organization's mission, reason for being, and purpose to all of the employees.

3. Increases employees' level of enthusiasm.

4. Emphasizes the use of employees' intelligence.

* Organizational Learning

In the last three years:

1. The organization has acquired and shared much new and relevant knowledge that provided competitive advantage. 
2. The organization's members have acquired some critical capacities and skills that provided competitive advantage.

3. Organizational improvements have been influenced fundamentally by new knowledge entering the organization (knowledge used).

4. The organization is a learning organization.

* Organizational Innovation

Indicate the degree of agreement or disagreement with respect to the following statements. In the past three years, indicate whether the following have grown rapidly:

1. Organization's emphasis on developing new products or services.

2. Rate of introduction of new products or services into the market.

3. Organization's spending on new product or service development activities.

4. Number of new products or services added by the organization and already on the market.

5. Number of new products or services that the organization has introduced for the first time on the market.

6. Investment in developing proprietary technologies.

7. Emphasis on creating proprietary technologies.

9. Organization's emphasis on technological innovation.

10. Organization's emphasis on pioneering technological developments in its industry.

* Organizational Performance

Relative to your main competitors, what is your firm's performance in the last three years in the following areas?

1. Organizational performance measured by return on assets (economic profitability or ROA).

2. Organizational performance measured by return on equity (financial profitability or ROE).

3. Organizational performance measured by return on sales (percentage of profits over billing volume).

4. Organization's market share in its main products and markets.

5. Growth of sales in its main products and markets.

\section{References}

Adair J. The challenge of innovation. England: The Talbot Adair Press; 1990.

Adler NJ. Psychological safety and learning behaviour in work teams. Administrative Science Quarterly $1983 ; 14(44): 350-83$.

AMADEUS (2004). Bureau van Dijk Electronic Publishing. Brussels.

Anderson JC, Gerbin DW. Structural equation modelling in practice: a review and recommended two-step approach. Psychological Bulletin 1988;103:411-23.

Antoncic B, Hisrich RD. Intrapreneurship: construct refinement and cross-cultural validation. Journal of Business Venturing 2001;16(5):495-527. 
Aragon Correa JA, Sharma S. A contingent resource-based view of proactive corporate environmental strategy. Academy of Management Review 2003;28(1):71-88.

Aragón JA, García Morales VJ, Cordón Pozo E. Leadership and organizational learning's role on innovation and performance: lessons from Spain. Industrial Marketing Management 2007;36(3):349-59.

Argyris C, Schön DA. Organizational learning II: theory, method, and practice. London: Addison-Wesley; 1996.

Armstrong JS, Overton TS. Estimating nonresponse bias in mail surveys. Journal of Marketing Research 1977;14:396403.

Baer M, Frese M. Innovation is not enough: climates for initiative and psychological safety, process innovations, and firm performance. Journal of Organizational Behavior 2003;24:45-68.

Bass BM. Two decades of research and development in transformational leadership. European Journal of Work and Organizational Psychology 1999;8(1):9-32.

Bass BM, Avolio BJ. MLQ multifactor leadership questionnaire technical report. Thousand Oaks: Sage Publications; 2000 .

Belliveau P, Griffin A, Somermeyer S. The PDMA toolbook for new product development. New York: John Wiley \& Sons, Inc.; 2002.

Bessant J, Buckingham J. Innovation and organizational learning: the case of computeraided production management. British Journal of Management 1993;4(4):219-37.

Bollen KA. Structural equations with latent variable. United States of America: WileyInterscience Publication; 1989.

Bueno E, Aragón JA, Salmador MP, García VJ. Tangible slack versus intangible resources: the influence of technology slack and tacit knowledge on the capability of organizational learning to generate innovation and performance. International Journal of Technology Management 2010;49(4):314-37.

Calantone RJ, Cavusgil TS, Zhao Y. Learning orientation, firm innovation capability, and firm performance. Industrial Marketing Management 2002;31:515-24.

Capron L. The long-term performance of horizontal acquisitions. Strategic Management Journal 1999;20:987-1018.

Choi B, Poon SK, Davis JG. Effects of knowledge management strategy on organizational performance: a complementarity theory-based approach. Omega 2008;36(2):235-51.

Coad AF, Berry AJ. Transformational leadership and learning orientation. Leadership and Organization Development Journal 1998;19(3):164-72.

Cohen WM, Levinthal DA. Absorptive capacity: a new perspective on learning and innovation. Administrative Science Quarterly 1990;35:128-52.

Colbert AE, Kristof-Broiatn AL, Bradley BH, Barrick MR. CEO transformational leadership: the role of goal importance congruence in top management teams. Academy of Management Journal 2008;51(1):81-96.

Conger JA. Charismatic and transformational leadership in organizations: an insider's perspective on these developing streams of research. The Leadership Quarterly 1999;10(2):145-79.

Damanpour F. Organizational innovation: a meta-analysis of effects of determinants and moderators. Academy of Management Journal 1991;34:555-90.

Danneels E, Kleinschmidt EJ. Product innovativeness from the firm's perspective: its dimensions and their relation with project selection and performance. The Journal of Product Innovation Management 2001;18:357-73.

Decarolis DM, Deeds DL. The impact of stocks and flows of organizational knowledge on firm performance: an empirical investigation of the biotechnology industry. Strategic Management Journal 1999;20:953-68. 
Deshpandé R, Farley JU, Webster E. Corporate culture, customer orientation, and innovativeness in Japanese firms: a quadratic analysis. Journal of Marketing 1993;57:23-7.

DiBella A, Nevis E, Gould J. Understanding organizational learning capability. Journal of Management Studies 1996;33:361-79.

Douglas TJ, Judge WQ. Total quality management implementation and competitive advantage. The role of structural control and exploration. Academy of Management Journal 2001;44(1):158-69.

Egri CP, Herman S. Leadership in the North American environmental sector: values, leadership styles, and contexts of environmental leaders and their organizations. Academy of Management Journal 2000;43(4):571-604.

Fein E, Tziner A, Vasiliu C. Age cohort effects, gender, and Romanian leadership preferences. Journal of Management Development 2010;29(4):364-76.

Fiol CM, Lyles MA. Organizational learning. Academy of Management Review 1985;10: 803-13.

Forrester RH. Capturing learning and applying knowledge: an investigation of the use of innovation teams in Japanese and American automotive firms. Journal of Business Research 2000;47:35-45.

García Morales VJ, Lloréns Montes FJ, Verdú Jover AJ. Antecedents and consequences of organizational innovation and organizational learning in entrepreneurship. Industrial Management \& Data Systems 2006;106(1-2):21-42.

García Morales VJ, Lloréns Montes FJ, Verdú Jover AJ. The effects of transformational leadership on organizational performance through knowledge and innovation. British Journal of Management 2008a;19(4):299-319.

García Morales VJ, Matías Reche F, Hurtado Torres N. Influence of transformational leadership on organizational innovation and performance depending on the level of organizational learning in the pharmaceutical sector. Journal of Organizational Change Management 2008b;21(2):188-212.

García-Morales VJ. Aprendizaje Organizacional: Delimitacióny Determinantes Estratégicos. Granada: Universidad de Granada; 2004.

Glick WH. Conceptualizing and measuring organizational and psychological climate: pitfalls in multilevel research. Academy of Management Review 1985;10:601-16.

Glynn MA. Innovative genius: a framework for relating individual and organizational intelligences to innovation. Academy of Management Review 1996;21:1081-111.

Gopalakrishnan S. Unraveling the links between dimensions of innovation and organizational performance. The Journal of High Technology Management Research 2000;11(1):137-53.

Gowen CR, Henagan SC, McFadden KL. Knowledge management as a mediator for the efficacy of transformational leadership and quality management initiatives in US health care. Health Care Management Review 2009;34(2):12940.

Gumusluoglu L, İlsev A. Transformational leadership, creativity, and organizational innovation. Journal of Business Research 2009;62(4):461-73.

Guns B. The Faster Learning Organization; Gain and Sustain the Competitive Edge. Pfeiffer and Company; 1996.

Hair JF, Anderson RE, Tatham RL, Black WC. Análisis Multivariante. Madrid: Prentice Hall; 1999.

Hall IA, Bagchi-Sen S. A study of R\&D, innovation, and business performance in the Canadian biotechnology industry. Technovation 2000;22:231-44.

Homburg C, Krohmer H, Workman JP. Strategic consensus and performance: the role of strategy type and marketrelated dynamism. Strategic Management Journal 1999;20:339-57. 
Hoopes DG, Postrel S. Shared knowledge, 'glitches', and product development performance. Strategic Management Journal 1999;20:837-65.

Hudges M, Morgan RR. Deconstructing the relationship between entrepreneurial orientation and business performance at the embryonic stage of firm growth. Industrial Marketing Management 2007;36:651-61.

Hurley RF, Hult GT. Innovation, market orientation, and organizational learning: an integration and empirical examination. Journal of Marketing 1998;62:42-54.

Inkpen AC, Crossan MM. Believing is seeing: joint ventures and organizational learning. Journal of Management Studies 1995;32:595-618.

Ireland RD, Hitt MA, Camp SM, Sexton DL. Integrating entrepreneurship actions and strategic management actions to create firm wealth. Academy of Management Executive 2001;15(1):49-63.

Irwin JG, Hoffman JJ, Lamont BT. The effect of the acquisition of technological innovations on organizational performance: a resource-based view. Journal of Engineering and Technology Management 1998;15:25-54.

Jöreskog KG, Sörbom D. LISREL VIII. Chicago: SPSS, Inc.; 1996.

Kanter RM. The change masters. New York: Simon \& Schuster; 1983.

Konrad AM, Linnehan F. Formalized HRM structures: Coordinating equal employment opportunity or concealing organizational practice? Academy of Management Journal 1995;38:787-820.

Koufteros X, Babbar S, Kaighobadi M. A paradigm for examining second-order factor models employing structural equation modeling. International Journal of Production Economics 2009;120:633-52.

Kozlowski SW, Klein KJ. A multilevel approach to theory and research in organizations: contextual, temporal and emergent processes. In: Klein KJ, Kozlowski SW, editors. Multilevel theory, research, and methods in organizations: foundations, extensions, and new directions. San Francisco: Jossey-Bass; 2000.

Lechner C, Frankenberger K, Floy SW. Task contingencies in the curvilinear relationships between intergroup networks and initiative performance. Academy of Management Journal 2010;53(4):865-89.

Lefebvre E, Lefebvre LA. Firm innovativeness and CEO characteristics in small manufacturing firms. Journal of Engineering and Technology Management 1992;9:243-77.

Lei D, Slocum JW, Pitts RA. Designing organizations for competitive advantage: the power of unlearning and learning. Organizational Dynamics 1999;28(3):24-38.

Lengnick-Hall CA. Innovation and competitive advantage: what we know and what we need to learn. Journal of Management 1992;18:399-429.

Lian Shao SW. Across-cultural test of the 'five-factor model of personality and transformational leadership'. Journal of Business Research 2006;59(8):936-44.

Lieberman M, Montgomery D. First mover advantages. Strategic Management Journal 1988;9:41-58.

Lööf H, Heshmati A. Knowledge capital and performance heterogeneity: a firm-level innovation study. International Journal of Production Economics 2002;76:61-85.

Maani K, Benton C. Rapid team learning: lessons from team New Zealand America's Cup campaign. Organizational Dynamics 1999;28(4):48-62.

Maastricht Economic Research Institution Innovation and Technology (MERIT). Annual Report. University of Limburg; 1992. 
Manz C, Barstein DT, Hostager TJ, Shapiro GL. Leadership and innovation: a longitudinal process view. In: Van de Ven A, Angle HL, Poole MS, editors. Research on the management of innovation: the Minnesota studies. New York: Harper and Row; 1989.

McColl-Kennedy JR, Anderson RD. Impact of leadership style and emotions on subordinate performance. Leadership Quarterly 2002;13:545-59.

McDonough EF. Investigation on factors contributing to the success of cross-functional teams. Journal of Product Innovation Management 2000;17:221-35.

McGill ME, Slocum JW, Lei D. Management practices in learning organizations. Organizational Dynamics 1992;21(1):5-17.

Meeus MTH, Oerlemans LAG, Hage J. Patterns of interactive learning in a high-tech region. Organization Studies $2001 ; 22: 145-72$.

Menguc B, Auh S, Shih E. Transformational leadership and market orientation: implications for the implementation of competitive strategies and business unit performance. Journal of Business Research 2007;60(4):314-21.

Mezias SJ, Glynn MA. The three faces of corporate renewal: Institution, revolution, and evolution. Strategic Management Journal 1993;14:77-101.

Murray JY, Kotabe M. Sourcing strategies of U.S. service companies: a modified transaction-cost analysis. Strategic Management Journal 1999;20:791-809.

Nandakumar MK, Ghobadian A, O'Regan N. Business-level strategy and performance. The moderating effects of environment and structure. Management Decision 2010;48(6):907-39.

Nonaka I, Takeuchi H. The knowledge-creating company: how Japanese companies create the dynamics of innovation. New York: Oxford University Press; 1995.

Ogbonna E, Harris LC. Leadership style, organizational culture and performance: empirical evidence from UK companies. International Journal of Human Resource Management 2000;11(4):766-88.

Podsakoff PM, Organ DW. Self reports in organizational research: problems and prospects. Journal of Management $1986 ; 12: 531-44$.

Podsakoff PM, MacKenzie SB, Lee JY, Podsakoff NP. Common method biases in behavioural research: a critical review of the literature and recommended remedies. The Journal of Applied Psychology 2003;88:879-903.

Porac JF, Thomas H. Taxonomic mental models in competitor definitions. Academy of Management Review $1990 ; 15(2): 224-40$

Rodriguez Ponce E. Leadership styles, strategic decision making and performance: an empirical study in small and medium-size firms. Interciencia 2007;32(8):522-8.

Sánchez R, Mahoney JT. Modularity, flexibility, and knowledge management in product and organization design. Strategic Management Journal 1996;17:63-76.

Sarros JC, Cooper BK, Santora JC. Building a climate for innovation through transformational leadership and organizational culture. Journal of Leadership \& Organizational Studies 2008;15(2):145-58.

Schein EH. On dialogue, culture, and organizational learning. Organizational Dynamics 1993;22(2):40-51.

Scott SG, Bruce RA. Determinants of innovative behavior: a path model of individual innovation in the workplace. Academy of Management Journal 1994;37:580-607.

Senge PM. The fifth discipline. New York: Doubleday Publ; 1990.

Senge P, Roberts C, Ross RB, Smith BJ, Kleiner A. The fifth discipline fieldbook. New York: Doubleday Publ; 1994. 
Shortell SM, Zajac EJ. Perceptual and archival measures of Miles and Snow's strategic types: a comprehensive assessment of reliability and validity. Academy of Management Journal 1990;33:817-32.

Slater SF, Narver JC. Market orientation and the learning organization. Journal of Marketing 1995;59(3):63-74.

Snyder WM, Cummings TG. Organization learning disorders: conceptual model and intervention hypotheses. Human Relations 1998;51:873-95.

Spector PE. Method variance in organizational research: truth or urban legend? Organizational Research Methods 2006;9:221-32.

Swieringa J, Wierdsma A. Becoming a learning organization. MA: Addison-Wesley; 1992.

Thomas JB, Sussman SW, Henderson JC. Understanding: 'strategic learning': linking organizational learning, knowledge management, and sensemaking. Organization Science 2001;12:331-45.

Tierney P, Farmer SM, Graen GB. An examination of leadership and employee creativity: the relevance of traits and relationships. Personnel Psychology 1999;52:591-620.

Tsai W, Ghoshal S. Social capital and value creation: the role of intrafirm networks. Academy of Management Journal 1998;41(4):464-76.

Tsang EWK. Organizational learning and the learning organization: a dichotomy between descriptive and prescriptive research. Human Relations 1997;50:73-89.

Tushman ML, Nadler DA. Organizing for innovation. California Management Review 1986;28(3):74-92.

Van de Ven AH. Central problems in the management of innovation. Management Science 1986;32:590-607.

Venkatraman N, Ramanujam V. Measurement of business performance in strategy research: a comparison of approaches. Academy of Management Review 1986;11(4):801-14.

Vorhies DW, Harker M, Rao CP. The capabilities and performance advantages of marketdriven firms. European Journal of Marketing 1999;33(11/12):1171-202.

Westphal JD, Fredickson JW. Who directs strategic change? Director experience, the selection of new CEOs, and change in corporate strategy. Strategic Management Journal 2001;22:1113-37.

Wick CW, Leon LS. From ideas to action: creating a learning organization. Human Resource Management 1995;34:299-311.

Yli-Renko H, Autio E, Sapienza HJ. Social capital, knowledge acquisition, and knowledge exploitation in young technology-based firms. Strategic Management Journal 2001;22:587-613.

Yukl G, Van Fleet DD. Theory and research on leadership in organizations. In: Dunnette MD, Hough LM, editors. Handbook of Industrial and Organizational Psychology, $2^{\text {nd }}$ ed, Vol. 3. Palo Alto, CA: Consulting Psychologists Press; 1991.

Zahra SA, Ireland RD, Hitt MA. International expansion by New Venture firms: international diversity, mode of market entry, technological learning, and performance. Academy of Management Journal 2000;43:925-50.

Zaltman G, Duncan R, Holbeck J. Innovations and organizations. New York: Wiley; 1973.

Zhu WC, Chew IKH, Spangler WD. CEO transformational leadership and organizational outcomes: the mediating role of human-capital-enhancing human resourcmanagement. Leadership Quarterly 2005;16(1):39-52.

Zollo M, Winter SG. Deliberate learning and the evolution of dynamic capabilities. Organization Science 2002;13:33951. 